\title{
Cañutos y soplidos \\ Tiempo y cultura en las zampoñas de las sociedades precolombinas de Arica ${ }^{1}$
}

\section{Time and Culture in Panpipes of the Precolumbian Societies in Arica, Chile}

\author{
por \\ Juan Chacama Rodríguez \\ Universidad de Tarapacá, Departamento de Antropología, Chile \\ jchacama@uta.cl \\ Alberto Díaz Araya \\ Universidad de Tarapacá, Departamento de Ciencias Históricas, Chile \\ albertodiaz@uta.cl
}

Este artículo intenta una aproximación a la temprana presencia de zampoñas en los valles occidentales de la macro región cultural conocida como Área Centro Sur Andina, utilizando como base antecedentes arqueológicos, etnohistóricos y musicológicos sobre los aerófonos andinos. Para este efecto, se han estudiado las colecciones arqueológicas almacenadas y documentadas en el Museo Universidad de Tarapacá, San Miguel de Azapa. El trabajo se focaliza en las relaciones cronológicas y culturales de las zampoñas precolombinas, sus momentos de aparición en la zona y su evolución en el tiempo.

Palabras clave: zampoñas precolombinas, Arica, Andes.

This article attempts an approach to the early presence of panpipes in the western valleys of the macrocultural region known as South Central Andes, on the basis of archaeological, ethnohistorical and ethnomusicological data on Andean wind instruments gathered from the study of the archaeological collections stored and documented in the Tarapacá University Museum at San Miguel de Azapa. The article is focused on establishing the chronological and the cultural relations of these Pre Columbian panpipes along with determining the time of their appearance in the area and their evolution over a period of time.

Key words: Pre Columbian panpipes, Arica, Andes.

${ }^{1}$ Artículo resultado de los Proyectos FONDECYT N ${ }^{\circ} 1071132$ y del Proyecto de Investigación Mayor de Ciencia y Tecnología de la Universidad de Tarapacá, $N^{\circ}$ 5730-10. Una revisión crítica del manuscrito original se realizó en el marco del proyecto FONDECYT $\mathrm{N}^{\circ} 1100132$. Asimismo, se agradece el apoyo del Convenio de Desempeño Universidad de Tarapacá-Mineduc.

Revista Musical Chilena, Año LXV, Julio-Diciembre, 2011, № 216, pp. 34-57 


\section{INTRODUCCIÓN. CAÑUTOS Y SOPLIDOS EN EL MUNDO ANDINO COLONIAL}

Esta investigación aborda la presencia de instrumentos musicales en diferentes contextos arqueológicos de la prehistoria de Arica, y se focaliza en la evidencia material de aerófonos andinos conocidos popularmente como zampoñas en ajuares mortuorios. Con el propósito de problematizar los diferentes escenarios temporales y socioculturales, se han examinado los contextos de data precolombina en los cuales se insertan las zampoñas. Esto permite la caracterización de las diferentes sociedades que en el pasado del norte chileno utilizaron aerófonos como parte del despliegue ceremonial que requería de sonoridades e instrumentación en el mundo andino (Díaz 2001).

La expresión latina zampoña (zapogna, sumponía, symphonia) ${ }^{2}$ se refiere a las flautas pastoriles de las campiñas griegas asociadas a la mitología del dios Pan (flautas de Pan) conocidas también como siringa (del griego síringos, sýrinx). Esta denominación también se ha utilizado para los aerófonos de filo andinos que constituyen las lacas, sikus, antaras, entre otras (Díaz y Mondaca 1998).

El término zampoña fue introducido por los colonizadores hispanos en el área andina. Asocia a los instrumentos musicales nativos de cañas con las denominaciones de los artefactos culturales europeos. Se trata de una reproducción de expresiones hispanas en contextos indígenas que incluso fueron utilizadas en ritos, animales o deidades (Zuidema 1995). Pese a la popularidad del término se refiere a expresiones andinas que encierran significados y contextos culturales diversos (Díaz 2001).

El término más generalizado en los Andes de Bolivia y Perú es la voz siku. Ludovico Bertonio a inicios del siglo XVII define este término como: "Sico: Unas flautillas atadas como ala de Organo...", "Sicona ayarichi phusatha. Tañer las dichasflautas cuya harmonia se llama Ayarichi” (Bertonio 1612:315-316). Los antecedentes proporcionados por el jesuita Bertonio ilustran las características del siku. Respeta la denominación local y compara la técnica de interpretación por el "soplido o viento" con el "órgano"s. La voz antara Diego Gonçalez Holguín en 1608 la traduce del quechua como "Flautillas juntas como órgano" (Gonçalez Holguín 1608 [1952]:28).

${ }^{2}$ Covarrubias [2006].

${ }^{3} \mathrm{El}$ empleo de la expresión siku en el norte de Chile sirve para identificar al instrumento que emplean los sikuris del altiplano chileno (Isluga y Cariquima). Se trata de un aerófono compuesto por catorce tubos de caña ordenados según la longitud de los tubos en forma horizontal, entrelazados por nervios de animal y lanas de colores. Este instrumento (siku, sikura o sikurphusa), estéticamente, es similar a la flauta de Pan. Su técnica de ejecución es en melodías a contrapunto, o medio tiempo tardío, una especie de "eco sonoro". Por lo tanto, los grupos sikuriada actúan como verdaderas orquestas, con doce integrantes y con diferentes tipos de sikus, según la longitud. Junto con presentar cada siku todos los tonos (notas), cada instrumentista (sikura) ejecuta una melodía, la que se responde (medio tiempo tardío) por otro sikura. Se establecen así diferencias con los aerófonos lacas, en las que cada músico (laquita), tiene solo una parte del instrumento, con tonos distintos, dependiendo de la escala musical. Al intercalar los tonos (notas) se conforman las melodías, una especie de diálogo musical o conversación del instrumento. Los sikuras, por su parte, interpretan otro instrumento a la vez. En el brazo que sostiene el siku llevan colgado un wankara-bombo, instrumento que es percutido por el otro 
En el norte de Chile el término que tiene mayor recurrencia tradicional y que se emplea con popularidad hasta nuestros días, es la expresión laca, que se entiende como denominación a los músicos como laquitas. "Laca" es una palabra de origen aymara, traducida como boca, diente, o lo que está dentro de la boca. $\mathrm{Al}$ respecto Bertonio señala que:

"Laca, v el Lacca: Boca.

Lacca hispi: labios.

Lacca huspi: labio de arriba

Laca llintta: geta.

Laca sanka: uno que tiene los labios partidos.

Lacca cchaca: Los dientes.

Lacca uyru: De boca chica" (Bertonio 1612 [1984]:183).

La denominación laca (boca) tiene estrecha relación con la técnica empleada para ejecutar los aerófonos de filo, ya que recae en la "emboquillación” y el soplido. Este vínculo se liga a su vez con la metodología de ejecución del instrumento, el manejo corporal del músico y la emisión directa de aire para rellenar los orificios de las cañas. De aquí surge una categoría de dominio programado de la boca y el tórax, que extraen el sonido y la tonalidad que la cavidad del cañuto presenta en estrecha relación con el diámetro y longitud del tubo (Díaz 1998). La adición entre instrumento y aire (sonido - tono) se encuentra en el idioma aymara bajo la expresión de phusa, la que se utiliza además en el área andina del norte chileno para designar a la zampoña. A saber:

"Phusatha: Soplar, y tambien tañer qualquiera istrumento que se toca soplando soplado como, Chirimi, Cornetas, Trompetas...

Phuskhatha: Soplar.

Phusantatha: Meter con el soplo.

Phusa sau, v el Phusa phusa: Una como caña, que aun nace por esta tiera.

Phusa kauña: Caña blanca como la de castilla” (Bertonio1612 [1984]:183).

A modo de síntesis, phusa se traduce como soplido o la acción de soplar. Existen algunas denominaciones toponímicas y leyendas de la zona en las que se señala esta palabra, como son a modo de ejemplo, Pusiri Collo (cerro de los músicos), en la localidad de Socoroma, al interior de Arica, y Pusiri en los alrededores de la misma localidad. Phusa, siku y laca constituyen tres denominaciones andinas para identificar a la zampoña, de las cuales laca es la más utilizada actualmente en el

brazo que acciona la maceta (percutor). Los ritmos que ejecutan son huayños o pasacalles bastante acompasados y su vestimenta es tradicional aymara, con grandes penachos adornados con plumas de suri (ñandú) denominados como chuco o jacha Chuco. Las sikura presentan distintos tamaños, dependiendo de su longitud y tonalidad, las Jach'a Pusa (tonos graves), contra (quintas) y likos (agudas). Mayores antecedentes en Díaz y Mondaca 1998. 
extremo norte de Chile ${ }^{4}$. Sólo por fines pedagógicos emplearemos la denominación zampoña para referirnos a los aerófonos precolombinos.

Las palabras en lengua aymara o quechua para designar las flautas popularizadas desde la época colonial como zampoñas poseen una profundidad temporal en cuanto a su presencia en épocas prehispánicas en el área andina. Los cronistas ibéricos realizaron interesantes descripciones sobre el uso y contexto de los aerófonos in comento, relatos que documentan el uso y función de las zampoñas durante el Tawantinsuyu.

En tal sentido, Pedro Cieza de León (1553) expone que durante algunas campañas militares de los inkas, las tropas se hacían acompañar por flautistas que entonaban himnos de guerra. Del mismo modo, cuando fallecía un miembro de la elite incaica, se entonaban himnos fúnebres con flautas. Se juntaban a los "principales del valle y hacian grandes lloros, y muchas de las mujeres se cortaban los cabellos hasta quedar sin ninguno y con atambores y salian con sones tristes cantando por aquellas partes por donde el señor solía festejarse más a menudo, para provocar a llorar a los oyentes" (Cieza de León, 1553 [1967:46]).

En los escritos de Francisco de Ávila (1598) se mencionan antaras confeccionadas de oro al relatar el momento en que el inka se dirige a todos los wacas (deidades) y a Macahuisa. En el mismo tenor, el cronista mestizo Felipe Guamán Poma de Ayala (1615 [1992]) registró ciertas prácticas de castigo utilizadas durante el Tawantinsuyu para la elaboración de zampoñas:

“el onceavo capitán Rumiñaui Cinchicona Auca, o sea traidor, fue un Capitán muy hábil y valeroso, hijo de un indio particular, pechero de bajo linaje y originario de Chinchaysuyo ... Cuentan que por traición mató al principe infante Illescas Inoc de cuya piel mando hacer un tambor; del cráneo hizo mate para beber chicha; de los huesos, Antara o flautilla; de los dientes y muelas un Quiro-Guallca, o sea gargantilla o collar" (Guamán Poma de Ayala 1615 [1992]:118)

Junto con referirse a la utilización de huesos como material para confeccionar zampoñas durante el Estado Inka, Guamán Poma de Ayala expone en otro texto que para las ceremonias de vinculos matrimoniales los esposos:

"se harán acompañar con personas que vayan bailando y cantando el Haylli, canto triunfal, los Taquies, cantos comunes. Tendrán la casa limpia con arcos triunfales de flores. Desde la iglesia hasta la casa recorriendo toda la calle se trasladarán los desposados, con mucho acompañamiento y, llevando comparsas que irán tocando trompetas,

${ }^{4}$ Otro término difundido en el centro del Perú corresponde a la "antara”, que es un tipo de aerófono (zampoña) que se caracteriza por el "soplido rajado". Está constituida por un cuerpo de material sólido como la cerámica, madera o piedra y estéticamente suelen ser similares a las lacas y a los sikus, pero con diferencias en las técnicas de ejecución y en la fabricación. Al respecto se señala que la antara era de uso individual y no colectivo como otras zampoñas con un sonido rajado de ejecución y no de "vibrato" y ronquido como en la laca, y cuya contextura es de un solo cuerpo, no utilizándose la caña para este instrumento. Aunque algunas investigaciones no resuelven completamente el problema de la Antara y su espacio tempo-cultural, mucho de los cronistas relacionaron, según los antecedentes que cada uno manejaba, los sinónimos estéticos de zampoña, siku y antara. Al respecto ver Pérez de Arce 1995. 
chirimiyas y flautas, sin que dejen de acudir a esta ceremonia los padres, con sus aguinaldos, limosnas y regalos de fruta" (Guamán Poma de Ayala 1615 [1992]:195)

A pesar de haber sido escrito en el año 1615, pareciera la descripción etnográfica de un matrimonio aymara contemporáneo ("cassarata"). De este modo, las zampoñas ocuparon (y aun lo hacen) un rol significativo en las prácticas cúlticas andinas, siendo la música un elemento neurálgico en el congregacionalismo ritual de las poblaciones indígenas (Díaz 2008).

Un dato no menor lo constituyen los términos haylli, voz aymara que expresa el canto en coplas lideradas por uno o más cantores y seguidas por la comparsa. A modo de ejemplo: "Hayllitha: Cantar quando aran o danzan o llevan muchos una viga... Diciendo uno y respondiendo otros" (Bertonio1612:534). En quechua la voz taqui expresa el mismo contenido semántico:

"Taquini o taquicuni: cantar solo o sin bailar.

Ñauraycuna taqui: La música.

Nauraycuna taquik cuna: Los músicos.

Taquicta hucarik: El que entona el canto o comienza primero o al que siguen todos.

Taquiyta qquencochini: Gargantear, contrapuntear" (Gonçalez Holguín (1608 [1952]:338)

Un dibujo de Felipe Guamán Poma de Ayala ilustra el uso en diferentes ceremonias de las zampoñas precolombinas, tal como puede apreciarse a continuación:

El Capítulo de los ritos y Ceremonias, pp. 297

322 [324] FIESTAS DE LOS ANDI SVIOS, CAIA CAIA, VARMI AVCA

[El qaya qaya, mujer enemiga] / Curi Pata, Anti / fiesta /

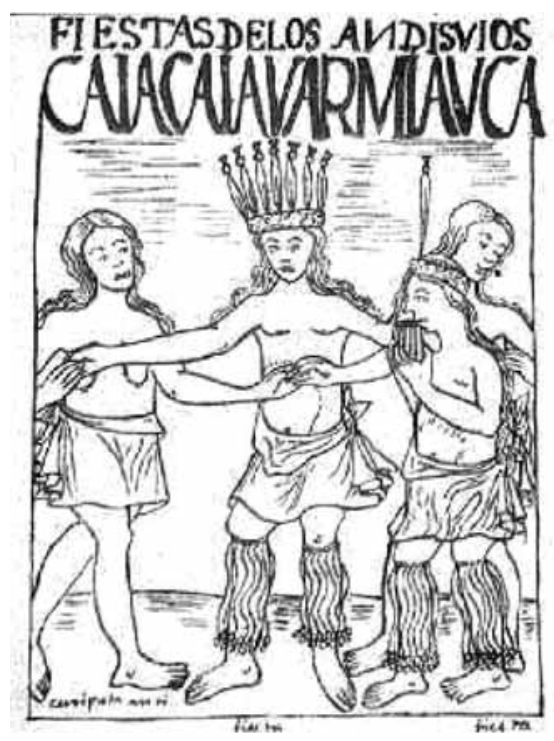


Siguiendo este entablado, el cronista Bernabé Cobo (1653) describe a los indios del Tawantinsuyu y los instrumentos musicales que utilizaban para las festividades nativas:

"Tenían para ello muchos instrumentos musicales, los cuales nunca tocaban sino en los bailes y borracheras, y todos hacían el son poco suave, y menos artificioso, pues cualquiera que se pone a tocarlos, a la primera lición queda maestro. El instrumento más general es el atambor, que ellos llaman Huáscar: hacíanlos grandes y pequeños, de un palo hueco tapado por ambos cabos con cuero de llama, como pergamino delgado y seco. Los mayores son como nuestras cajas de guerra, pero más largos y no tan bien hechos; los menores como una cajeta pequeña de conserva, y los medianos como nuestros tamborinos.

Tocándolo con un solápalo, el cual a veces por gala está cubierto de hilo de lana de diferentes colores; y también suelen pintar y engalanar los atambores. Tócanlo así hombres como mujeres; y hay bailes al son de uno solo y otros en que cada uno lleva atambor pequeño, bailando y tocando juntamente. También usan cierta suerte de adufes, nombrados huancartinya; y pífano, llamado pincollo. Antara es otro género de flauta corta y ancha. Anaquena es una caña sola como flauta, para contar endechas. Quepa es una suerte de trompetilla que hacen de un calabazo largo. Usan también en sus bailes tocar un instrumento compuesto de siete flautillas, poco más o menos, puestas como cañones de organos, juntas y desiguales, que la mayor será larga un palmo y las demás van decreciendo por su orden: llaman a este instrumento ayaríchic, y tócanlo puesto sobre el labio bajo y soplando en las dichas flautillas, con que hacen un sordo y poco dulce sonido. Tocan asimismo caracoles y otros instrumentos de menos cuenta.

Fuera de las galas y arreos que sacan en sus bailes, se ponen en la garganta del pie sartas de sus cascabeles, que son de dos o tres maneras. Los incas los usaban antiguamente de ciertas cáscaras de frísoles grandes y de colores que hay en las provincias de los Andes, y llamábanse estos cascabeles Zacapa. Chanrara son otros que hacían de cobre y plata como campanillas. Los más comunes eran los que se llaman churu, los cuales eran de caracoles de mar larguillos y de varios colores" (Cobo 1653 [1964]: 270) (cursiva agregada).

Las anteriores citas dejan entrever la asociación que realiza Cobo al comparar abiertamente los "cañones de un órgano" utilizados en los templos o catedrales coloniales con la composición de tonos de los aerófonos andinos. Sin lugar a duda esta analogía entre el órgano (barroco) y la zampoña (andina), responde a patrones similares en la obtención de los sonidos y las tonalidades de los instrumentos: el soplido.

A la vez, denota el grado de atención que significaba para los españoles la calidad orquestal de los conjuntos nativos de zampoñeros, en una época en que el órgano era el único instrumento que podía lograr armonías polifónicas.

Bartolomé Álvarez (1588), cura doctrinero en el altiplano de Sabaya (Bolivia), localidad colindante con el poblado de Isluga (Chile), describe en el siglo XVI el rito que los indios realizaban desde el tiempo de los incas en una ceremonia que transcribe in extenso:

"Para sacrificar por el bien de las sementeras tomaban un animalejo que era a manera de perrillo de falda -pequeño de pies y talle raro, no lamido [=no flaco]- que en 
esta tierra les dio su pecado para su mal, que no había otra generación de perros. Éstos tenían naturalmente una canal por cima de las narices, honda hasta el labio, de suerte que apartaban las ventanas de sus narices una de otra muy divinamente, y las ventanas mostraban anchura e redondez de suerte que hacían visión [=daban apariencia] extraña: el hocico corto, la oreja pequeña y aguda, gordilla cola corta, ojos vivos mucho, que parecía cosa rellena. Con éste tomaban cuatro cuyes sin mácula, a los cuales, ahogaban retorciéndoles las cabezas hasta quebrar el hueso por la nuca; y luego les abrían el cuero por entre las piernas, de manera que, sacándoles todos los huesos y carne -juntos [s] de pies y manos, pescuezo y cuerpo- por aquella abertura, queda el cuero sin romper más. E hinchando aquellos cuercillos, de paja del campo los embutían. Y espetándolos [=empalándolos] en unas puntas de varas altas, los mandaban llevar y poner encima de cuatro cerros altos, hincadas las varas en modo de cuatro esquinas, de suerte que tomaban las chácaras en medio. Y el chullo de la misma manera: lo plantaban en algún altillo, si le había, en medio de todas las chácaras.Y entretanto que estas varas se sitiaban [sic. =ंsituaban?] en el lugar donde habían de estar, tomaban la carne de aquellos animales y enterrábanla en la tierra; de suerte que éste era el sacrificio hecho a la tierra, y el de los cueros a la uaca. Luego se sentaban a comer de fiesta lo que para ello tenían aparejado, con gran regocijo y contento; habiendo gran cantidad de açua, comian bravamente y bebian, porque era fiesta principal. En acabándose las comidas, se levantaban a danzar y cantar tañendo atambores muchos, según había los corros de sus danzas. Tenían algunas a manera de flautas que las hacían sonar a soplos, que no tenía más sonido ni música que lo que hacía un soplo: propia música de visunatos" (Álvarez 1588 [1998]103-104) (cursiva agregada).

Uno de los antecedentes más significativos sobre la técnica de ejecución de las zampoñas prehispánicas lo entrega el Inca Garcilaso de la Vega a comienzos del siglo XVII. Al respecto señala que en Collasuyu, sector sur del Tawantinsuyu, los indígenas aymaras:

"de música alcanzaron algunas consonancias, las cuales tañían los indios Collas, o de su distrito, en unos instrumentos hechos de cañutos de caña, cuatro o cinco cañutos atados a la par; cada cañuto tenía un punto más alto que otro, a manera de organos. Estos cañutos atados eran cuatro, diferentes unos de otros. Uno dellos andaba en puntos bajos y otro en más altos y otro en más y más, como las cuatro voces naturales: triple, tenor, contralto y contrabajo. Cuando un indio tocaba un cañuto, respondía el otro en consonancia de quinta o de cualquiera, y luego el otro en otra consonancia y el otro en otra, unas veces subiendo a los puntos más altos y otras bajando a los bajos, siempre en compás. No supieron echar glosa con puntos diminuidos; todos eran enteros de un compás. Los tañedores eran indios enseñados para dar música al rey y a los señores de vasallos, que, con ser tan rústica la música, no era común, sino que la aprendían y alncanzaban con su trabajo. Tuvieron flautas de cuatro a cinco puntos como la de los pastores; no los tenían juntos en consonancia, sino cada uno de por sí, porque no los supieron concertar. Por ellos tañían sus cantares, compuestos en verso medido, las cuales, por la mayor parte, eran de pasiones amorosas, ya de placer, ya de pesar, de favores o disfavores de la doña" (Garcilaso de la Vega 1609 [1991]:119).

Garcilaso describe a cabalidad la estructura musical, el material de los aerófonos, la consonancia y la conformación del grupo de zampoñeros. Además, 
es posible advertir en el relato un cierto manejo de la composición musical y conocimientos de las estructuras melódicas. Presentan antecedentes de dos tipos de lenguaje y estructura musical en torno a los cañutos y soplidos: el europeo y el andino.

De esta manera, tanto Garcilaso de la Vega como otros cronistas del mundo andino colonial dieron cuenta del contexto cultural en el cual las zampoñas se encontraban insertas. Queda en evidencia que este instrumento era propio de los Andes y la complejidad de su estructura hace suponer una larga data de desarrollo. Este último punto merece ser examinado, para lo cual haremos usos de la evidencia arqueológica presente en el área de Arica, norte de Chile ${ }^{5}$.

\section{LOS CAÑUTOS EN ARICA. UNA SÍNTESIS ARQUEOLÓGICA}

$\mathrm{El}$ extremo norte de Chile posee una historia precolombina que se remonta al $10^{\circ}$ milenio antes del presente. En dicho lapso se sucedieron diferentes formas de organizaciones sociales, políticas y económicas. Estas abarcan desde las tempranas bandas de cazadores, recolectores, pescadores que surcaron el litoral y las tierras altas en busca de alimentos y cotos de caza o pesca, hasta la influencia de complejos estados políticos como lo fuera Tiwanaku entre el 500 y 1000 d.C. y el estado Inca entre 1400 y 1500 d.C. (Santoro, y Ulloa 1985; Santoro et al. 2001, Chacama 2004). A continuación se presenta un breve resumen de la larga presencia humana en el extremo norte de Chile.

En términos generales y, basados en la secuencia de valles y litoral costero, se distinguen cinco grandes períodos en la prehistoria del norte grande. Un período arcaico que se extiende casi desde el $9^{\circ}$ al $3^{\text {er. }}$ milenio antes del presente $(c f$. Llagostera 1979, 1982, 1989; Muñoz y Chacama 1982, 1993, 1997; Standen et al. 2004). El período se caracteriza por una economía y modo de vida centrados en la caza-pesca y recolección, especialmente de productos marítimos. Su componente cultural más relevante fue la técnica de momificación compleja conocida como Chinchorro, técnica que caracteriza en gran medida todo el período Arcaico Medio (ca. 7000-4000 años a.P.) (cf. Allison et al. 1984; Arriaza 1995, 2003; Bittman 1982; Bittman y Munizaga 1976, 1977; Rivera 1995; Standen 1991; Standen et al. 1984, entre otros). En las tierras altas y durante la misma época ocupan las serranías y altiplanicie bandas de cazadores-recolectores. Durante los primeros milenios estos cazadores aprovecharon en forma indiscriminada el conjunto de recursos faunísticos disponibles en el medio. En la medida en que transcurrieron los milenios, estas bandas de cazadores se especializaron en grandes mamíferos como los camélidos andinos (Santoro 1989; Santoro y Núñez 1987).

Una serie de cambios culturales, especialmente tecnológicos, abren paso a una etapa de agricultura inicial o experimental con aportes provenientes del altiplano circunlacustre (o circumtiticaca), conocida para la zona en cuestión como período

\footnotetext{
${ }^{5}$ Un trabajo pionero sobre la contextualización de instrumentos musicales de origen precolombino en Chile, lo constituye el texto de Grebe 1974, cuya información utilizamos como referencia en nuestra problematización.
} 
Intermedio Temprano o también período Formativo (Muñoz 1989, 2002, 2004a, 2004b). Esta etapa de agricultura inicial, junto con un proceso de transición a un sedentarismo propio de sociedades agrícolas, cambió paulatinamente el eje de asentamiento poblacional desde la costa hacia los valles fértiles. Se han reconocido, para dicho período, dos grandes momentos. El primero, está más relacionado con la tradición de pescadores, denominado Formativo Temprano (ca. 1000-500 a.C.) ${ }^{6}$. El segundo momento o Formativo Tardío (ca. 500 a.C.-500 d.C.) cuenta con una mayor presencia de elementos que denotan una influencia altiplánica. Su mayor exponente es la fase cultural Alto Ramírez y los túmulos funerarios asociados a dicha fase (Muñoz 1989; Santoro 2000) ${ }^{7}$.

A partir del período Formativo Tardío, las influencias altiplánicas en el área comienzan a ser más frecuentes y sistemáticas. Una gran parte del área Centro Sur Andina quedó bajo la influencia del estado altiplánico de Tiwanaku (Berenguer y Dauelsberg 1989; Kolata 1993; Chacama 2004). Este momento de la prehistoria de los valles del norte grande, se caracterizó por una alta movilidad y tráfico interregional (Núñez 1976; Núñez y Dillehay 1978; Berenguer 2004). Esto permitió un intercambio intensivo de bienes económicos y suntuarios entre las tierras altas del altiplano y los valles costeros. Del mismo modo, las ideologías imperantes de la cuenca del Titicaca fueron difundidas hacia los valles occidentales e incorporadas a sus poblaciones mediante el uso de diferentes prácticas y objetos rituales o de prestigio, i.e., vestimenta, tocados, imágenes rupestres, etc. ( $c f$. Berenguer 2000; Chacama 2001; Chacama y Espinosa 2000; Rivera 1984).

Por otra parte, la forma de relación entre ambas esferas culturales: la altiplánica representada por el hegemónico estado de Tiwanaku y la de valles occidentales, ha sido objeto de múltiples debates entre distintos investigadores a través del tiempo. Entre estas formas de relación se pueden señalar las siguientes. 1) Una acción militar de conquista por parte del estado de Tiwanaku sobre las sociedades aledañas (tesis militarista de Ponce, en Berenguer y Dauelsberg 1989:142-143), 2) Instalación de colonias altiplánicas en los valles occidentales (Berenguer y Dauelsberg 1989, Mujica et al. 1983) ${ }^{8}$, 3) Intercambios "comerciales" ( modo altiplánico de Browman y movilidad complementaria convergente de Núñez y Dillehay en Berenguer y Dauelsberg 1989:143-146), 4) Incorporación de territorios vía centros provinciales administrativos (valle de Moquegua) (Golsdtein 1989).

El orden imperante de Tiwanaku en los Andes del Sur se prolongó por casi 500 años, hasta que alrededor del año 1000-1100 d.C. se produjo su colapso y cesó su influencia regional (Berenguer y Dauelsberg 1989; Kolata 1993). Luego

${ }^{6}$ El Formativo Temprano involucra las fases culturales conocidas como Faldas del Morro (Dauelsberg 1985), Laucho (Focacci 1974) y Azapa (Santoro 1980a, 1980b, 1981).

${ }^{7} \mathrm{El}$ investigador M. Rivera posee una propuesta alternativa en cuanto a los diferentes momentos del período Formativo. Para este autor, el período Formativo del extremo norte de Chile se encuentra representado mediante la fase Alto Ramírez, de fuerte raigambre altiplánica. Esta fase cultural se encontraría dividida en tres grandes momentos, Alto Ramírez I (que correspondería a las fases Azapa, Faldas del Morro y Laucho), Alto Ramírez II (Alto Ramírez propiamente tal) y Alto Ramírez III (Rivera 1980).

${ }^{8}$ La propuesta de colonias altiplánicas en los valles del norte de Chile ha sufrido variantes internas que afectan el grado y alcance del término colonia (cf. Berenguer 2000; Goldstein 1995/96; Uribe 1999). 
del colapso del estado de Tiwanaku, diversos grupos locales, ubicados en la esfera de influencia de dicho estado, buscaron su preeminencia regional. Esta época es conocida como de los Desarrollos Regionales y también como período Intermedio Tardío (ca. 1000-1400 d.C.) (Santoro 2001; Santoro et al. 2001; Schiappacassse et al. 1989). Se define como "un traslapo de influencias Tiwanaku y por la larga tradición altiplánica vigente desde tiempos tempranos hacia espacios foráneos al ámbito de recursos circunlacustre, que ofrecen recursos agrarios, forrajeros y de recolección" (Schiappacasse et al. 1989:181). En la subregión de valles occidentales los grupos culturales tendrían una organización social la cual correspondería a sociedades de rango, específicas al nivel de aldea, organizada en clanes o linajes (Schiappacasse et al. 1989:186). Una de las características de este período es la continua e intensa interacción que establecen las sociedades de valles occidentales con las sociedades altiplánicas; especialmente en la precordillera de Arica en la que es posible apreciar la imbricada relación existente entre ambas sociedades (Muñoz y Chacama 2006).

Finalmente, a partir de la mitad del siglo XV, se deja sentir en una vasta zona de los Andes, incluida nuestra área de estudio, la presencia Inca. Respecto a este evento cultural una de las preguntas más frecuentes ha sido el tipo de dominación que ejerció el Inca en la zona. A. Llagostera plantea un dominio incaico indirecto en la vertiente occidental de los Andes vía poblaciones altiplánicas (Llagostera 1976), hipótesis a la cual se han sumado otros autores, al menos para el norte de Chile ( $c f$. Muñoz et al. 1987a; Muñoz et al. 1987b; Niemeyer y Shiappacasse 1988; Shiappacasse y Niemeyer 1997, 2002). Sin embargo, a la luz de nuevos registros, se ha comenzado a postular un dominio más directo del estado Inca, especialmente para las tierra altas de la segunda región del país (Uribe 2004; Uribe y Adan 2004). No obstante la problemática anteriormente expuesta, lo que interesa como marco referencial para esta investigación es resaltar el hecho que al igual que en épocas anteriores, durante el período Tardío, Arica y sus valles se vieron estrechamente vinculados a los desarrollos culturales de áreas vecinas, en este caso al desarrollo y expansión del Tawantinsuyu.

Esta breve síntesis de la prehistoria de los valles occidentales ha sido delineada a partir de la experiencia investigativa en un valle, el de Azapa. Dicha secuencia cultural nos provee el marco contextual en el cual se inserta la investigación propuesta en torno a la historia de las zampoñas precolombinas.

Uno de los puntos relevantes de la reseña expuesta es que a partir del período Formativo Tardío, se da inicio a una intensa interacción cultural entre las tierras altas del altiplano y los valles occidentales. Producto de dicha interacción los valles occidentales del extremo norte de Chile se ven involucrados a través del tiempo en diferentes esferas de influencia política. Las más destacables son las de Tiwanaku en el Horizonte Medio y la expansión incaica en el Horizonte Tardío. Es en esta continua interacción entre tierras altas y tierras bajas que se generan los procesos culturales de los valles occidentales y con ello los diferentes tipos de organización social que tuvieron lugar en ellos. Esto sirve de contexto para los aerófonos que analizaremos en este trabajo. 


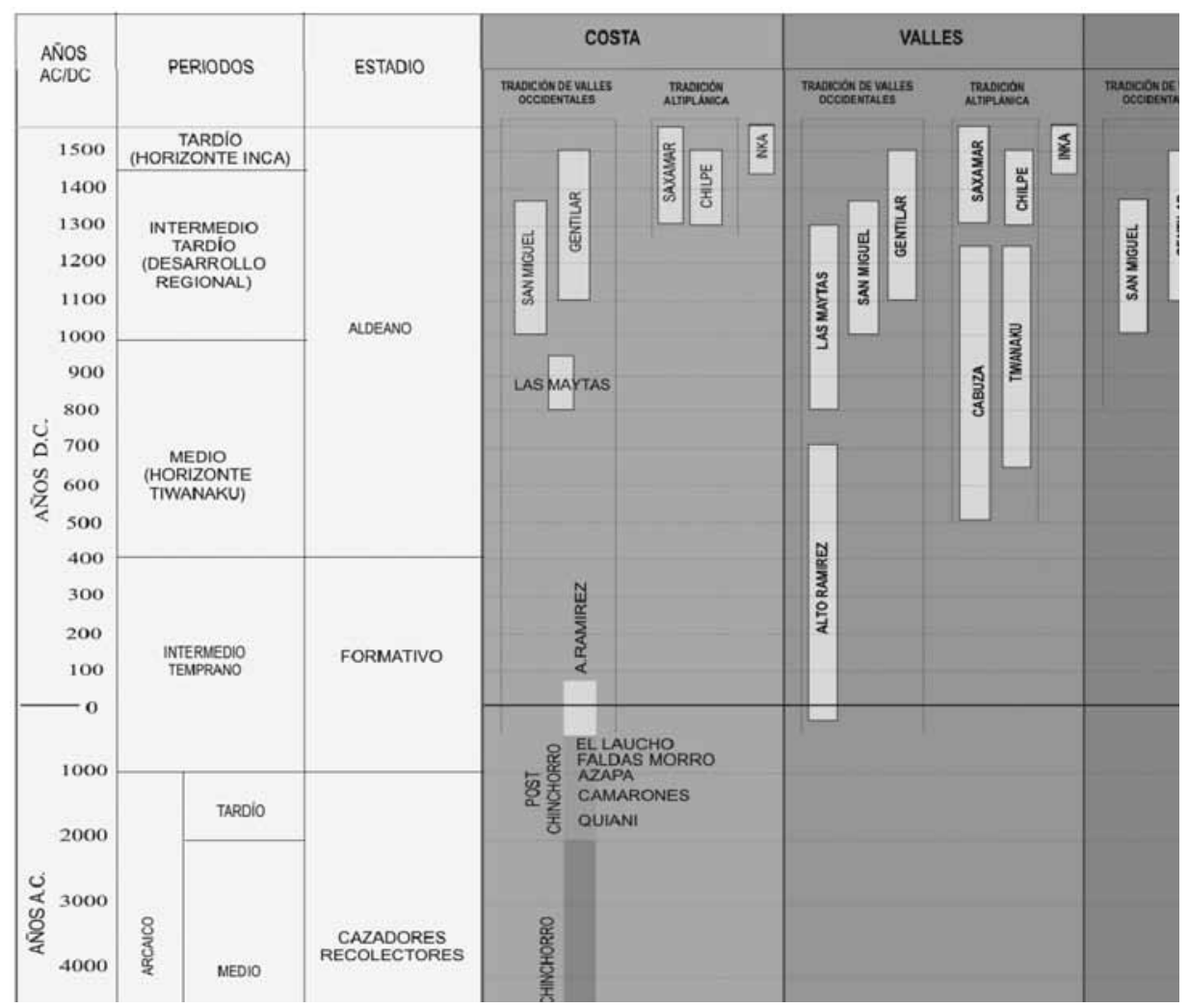

Secuencia cronológica prehispana. Región Arica-Parinacota.

\section{CONTEXTOS Y PROCEDENCIA DE LAS ZAMPOÑAS PRECOLOMBINAS DE ARICA}

En la zona de Arica, durante varias décadas de investigación, se han excavado numerosos cementerios precolombinos de los cuales provienen un significativo números de zampoñas. Esta situación ha permitido seguir parte de la historia de este instrumento en los valles occidentales del extremo norte de Chile. Sus primeras evidencias, la asociación tempo-cultural, las relaciones contextuales son variantes que a continuación se analizan.

Una muestra de ocho colecciones arqueológicas ${ }^{9}$ debidamente registradas servirán en este trabajo para contextualizar un conjunto de zampoñas prehispánicas. Las colecciones en cuestión provienen tanto del valle de Azapa como de la costa de Arica. Fueron excavadas en diferentes momentos y se encuentran hoy depositadas en el Museo San Miguel de Azapa de la Universidad de Tarapacá.

${ }^{9}$ Se considera una colección arqueológica al conjunto de materialidades provenientes de un mismo sitio arqueológico. Para este estudio las colecciones arqueológicas analizadas corresponden a diversos cementerios de la zona de Arica. 
TABLA N ${ }^{\circ} 1$

COLECCIONES ARQUEOLÓGICAS ESTUDIADAS

\begin{tabular}{|c|c|c|c|}
\hline Sitio (colección) & Excavado por & Año excavación & Publicación \\
\hline Playa Miller 3 (PlM. 3) $)^{10}$ & Guillermo Focacci & 1969 & Inédita $^{11}$ \\
\hline Playa Miller 4 (PIM. 4) & Guillermo Focacci & 1969 & Inédita $^{\text {Azapa 6 (Az. 6) }}$ \\
\hline Guillermo Focacci & 1972 & $\begin{array}{c}\text { Focacci 1990 } \\
\text { Fondecyt 194005912 }\end{array}$ \\
\hline Azapa 71a (Az. 71a) & Guillermo Focacci & 1974 & Fondecyt 1940059 \\
\hline Azapa 15 (Az 15) & Guillermo Focacci & 1973 & Inédita \\
\hline Azapa 71b (Az. 71b) & Calogero Santoro & 1975 & $\begin{array}{c}\text { Santoro (1980) } \\
\text { Fondecyt 1940059 }\end{array}$ \\
\hline Azapa 141 (Az. 141) & Percy Dauelsberg & 1985 & Fondecyt 1940059 \\
\hline
\end{tabular}

El cementerio Az. 71 (Azapa 71a y Az71b) se ubica en la banda norte del río San José a la altura del km 12 del valle de Azapa. Por su parte Az. 6 se ubica sólo a $500 \mathrm{~m}$ al este de Az. 71. Ambos sitios se encuentran en el área arqueológica de San Miguel de Azapa caracterizada por un conjunto de vertientes producto de la confluencia entre dicho valle y la quebrada del Diablo. El sitio Az. 141 se encuentra a $25 \mathrm{~km}$ de la costa y está ubicado en la banda norte del río San José, a media ladera del valle. El cementerio Az. 15 se encuentra en la confluencia del valle de Azapa con la quebrada de las Llocllas, en las inmediaciones de la aldea Inca catalogada bajo la misma sigla (Az 15). En la costa, PIM. 3 y PIM. 4 están situados uno al lado de otro en la línea costera a $2 \mathrm{~km}$ al sur de la ciudad de Arica, en la ladera oeste de las estribaciones de la cordillera de la Costa que caen sobre el actual balneario La Lisera.

\footnotetext{
${ }^{10}$ Las siglas entre paréntesis son una convención para designar los sitios arqueológicos. Las siglas Az. corresponden a sitios provenientes del valle de Azapa y las siglas Pl.M a sitios provenientes del litoral.

${ }^{11}$ Las colecciones señaladas como inéditas no han sido publicadas en forma íntegra. Solamente se han extraído aspectos aislados de ellas al interior de publicaciones de diversa índole.

${ }^{12}$ Las colecciones Az6, Az 141 y Az 71a y b fueron analizadas integralmente en el proyecto FONDECYT 1940059, coordinado por uno de los autores, profesor Juan Chacama R. Sus resultados se encuentran en los respectivos informes de avance.
} 


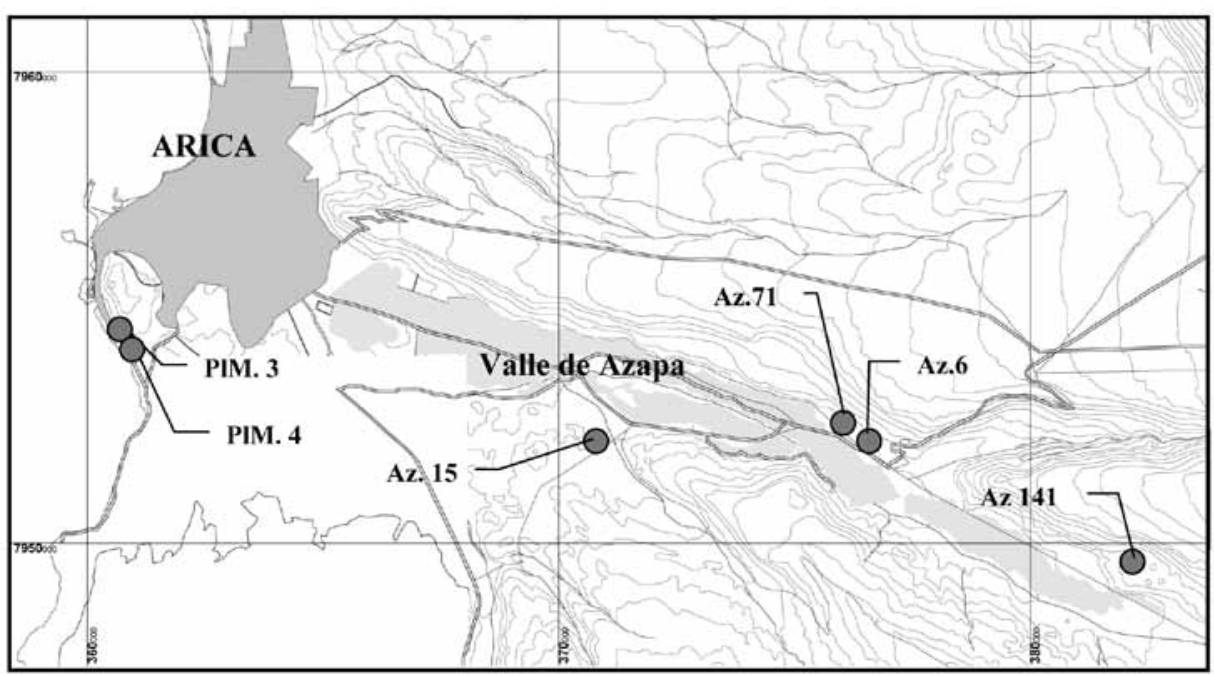

Mapa 1. Distribución espacial de sitios arqueológicos analizados.

De las colecciones señaladas se documentaron 110 zampoñas, ya sea como instrumento completo o parte de él, con sus correspondientes contextos según se detallan a continuación ${ }^{13}$.

TABLA N ${ }^{\circ} 2$

CANTIDAD DE ZAMPOÑAS Y CONTEXTOS POR SITIO ARQUEOLÓGICO

\begin{tabular}{|c|c|c|c|}
\hline Sitio & $\mathbf{N}^{\mathbf{0}}$ zampoñas & $\mathbf{N}^{\mathbf{0}}$ contextos & $\begin{array}{c}\text { \% zamponas } \\
\mathbf{v} / \mathbf{s} \text { contextos }\end{array}$ \\
\hline Azapa 141 (Az.141) & 4 & 55 & 7,27 \\
\hline Azapa 15 (Az.15) & 12 & 100 & 12,00 \\
\hline Azapa 6 (Az.6) & 15 & 206 & 7,28 \\
\hline Azapa 71a (Az.71a) & 15 & 200 & 7,50 \\
\hline Azapa 71b (Az.71b) & 10 & 607 & 1,65 \\
\hline Azapa 75 (Az. 75) & 7 & 136 & 5,15 \\
\hline Playa Miller 3 (PlM.3) & 23 & 247 & 9,31 \\
\hline Playa Miller 4 (PlM.4) & 24 & 171 & 14,04 \\
\hline Total & 110 & 1.722 & $\begin{array}{c}\text { Promedio de zampoñas } \\
\text { por sitio 8,02\% }\end{array}$ \\
\hline
\end{tabular}

${ }^{13}$ Las colecciones analizadas corresponden a cementerios y los contextos a sepulturas. Salvo ocasiones específicas, cada sepultura contiene a un individuo. 
La tabla $\mathrm{N}^{\circ} 2$ refleja la distribución de las 110 zampoñas documentadas. Se puede apreciar que PIM3 tiene muchas más zampoñas (23) que Azapa 141 (4). No obstante, tomando en cuenta el número de contextos de cada sitio, se percibe solo una ligera ventaja de PIM3 (9,31\%) sobre Azapa 141 (7,27\%). Visto de este modo el sitio con mayor incidencia de zampoñas es PIM4 con un 14,04\% y la media porcentual de zampoñas para el conjunto de sitios, considerando todos los contextos y zampoñas documentadas, es de 8,02\%.

Lo anterior nos entrega una primera aproximación a este instrumento musical. Es dable señalar que la zampoña es un bien escaso dentro de las poblaciones prehispánicas del extremo norte de Chile. Si bien, a primera vista, existe un número no despreciable de zampoñas, en relación a sus contextos de procedencias este número no sobrepasa el $8 \%$ en promedio. De cada 100 individuos sólo 8 de ellos fueron ofrendados con este instrumento.

\section{RELACIONES CRONO-CULTURALES DE LAS ZAMPOÑNA}

Culturalmente los cementerios analizados representan varios momentos de la prehistoria del extremo norte de Chile. El cementerio Az. 71 (Azapa 71a y Az71b) posee contextos funerarios que van desde el período Formativo al período Intermedio Tardío, constituyendo una secuencia cultural de casi 2000 años (ca. 1000 a.C.-1350 d.C.) (Santoro 1980a).

Por su parte Az. 6, ubicado sólo $500 \mathrm{~m}$ al este de Az. 71, es un cementerio un tanto más pequeño que el anterior. Presenta contextos funerarios pertenecientes mayoritariamente al período Medio y una breve porción al Intermedio Tardío (Focacci 1993). Az. 141, ubicado en la banda norte del río, a media ladera del valle y a $25 \mathrm{~km}$ de la costa, es un cementerio exclusivamente con contextos pertenecientes al período Medio. El cementerio Az. 15 se encuentra en la confluencia del valle de Azapa con la Quebrada de las Llocllas y es un sitio exclusivamente vinculado al período tardío o Inca. En la costa, PIM. 3 y PIM. 4 situados uno al lado del otro en la línea costera a $2 \mathrm{~km}$ al sur de la ciudad de Arica, se ubican en la ladera de las estribaciones de la cordillera de la Costa que caen sobre el actual balneario La Lisera. Estos cementerios poseen contextos culturales vinculados al período Intermedio Tardío.

La tabla $\mathrm{N}^{\circ} 3$ evidencia un amplio espectro cultural involucrado en la muestra de sitios arqueológicos utilizados en este análisis, que comprende las fases culturales Azapa, Alto Ramírez, Cabuza, Maitas-Chiribaya, San Miguel, Gentilar e Inca y el estilo cerámico Tiwanaku. Esta situación abarca aproximadamente unos 2500 años (ca. 1000 a.C.-1500 d.C.).

A continuación se precisa la relación cultural de los 110 aerófonos (zampoñas) documentados respecto de los componentes culturales de cada uno de los sitios de proveniencia. 
TABLA N ${ }^{\circ} 3$

RESUMEN DE COMPONENTES CULTURALES POR SITIO

\begin{tabular}{|c|c|c|}
\hline Sitio & $\begin{array}{l}\text { Períodos culturales } \\
\text { presentes en el sitio }\end{array}$ & Fases culturales presentes en el sitio \\
\hline \multirow{4}{*}{ Azapa 7la } & \multirow{3}{*}{ Medio } & Cabuza \\
\hline & & Tiwanaku \\
\hline & & Maytas Chiribaya \\
\hline & Intermedio Tardío & San Miguel \\
\hline \multirow{6}{*}{ Azapa 71b } & \multirow{2}{*}{ Formativo } & Azapa \\
\hline & & Alto Ramírez \\
\hline & \multirow{3}{*}{ Medio } & Cabuza \\
\hline & & Tiwanaku \\
\hline & & Maytas Chiribaya \\
\hline & Intermedio Tardío & San Miguel \\
\hline \multirow{3}{*}{ Azapa 6} & \multirow{2}{*}{ Medio } & Cabuza \\
\hline & & Maytas Chiribaya \\
\hline & Intermedio Tardío & San Miguel \\
\hline \multirow{2}{*}{ Azapa 141} & \multirow{2}{*}{ Medio } & Cabuza \\
\hline & & Tiwanaku \\
\hline Azapa 15 & Tardío & Inca \\
\hline \multirow{2}{*}{ Playa Miller 3} & \multirow{2}{*}{ Intermedio Tardío } & San Miguel \\
\hline & & Gentilar \\
\hline \multirow{2}{*}{ Playa Miller 4} & \multirow{2}{*}{ Intermedio Tardío } & San Miguel \\
\hline & & Gentilar \\
\hline
\end{tabular}

TABLA N ${ }^{\circ} 4$

CANTIDAD DE ZAMPONAS POR FASES Y PERÍODOS CULTURALES

\begin{tabular}{|c|c|c|c|c|c|c|}
\hline \multirow{2}{*}{ Sitios } & \multicolumn{2}{|c|}{ Período Medio } & \multirow{2}{*}{\begin{tabular}{|c|}
$\begin{array}{c}\text { Período Intermedio } \\
\text { Tardío }\end{array}$ \\
San Miguel / Gentilar \\
\end{tabular}} & \multirow{2}{*}{$\begin{array}{c}\begin{array}{c}\text { Período } \\
\text { Tardío }\end{array} \\
\text { Inca }\end{array}$} & \multirow{2}{*}{$\begin{array}{c}\text { Contextos } \\
\text { indeterminados }\end{array}$} & \multirow{2}{*}{ Total $^{14}$} \\
\hline & Cabuza & Maytas & & & & \\
\hline Az 141 & $2^{15}$ & & & & 2 & 4 \\
\hline $\mathrm{Az} 15$ & & & & 12 & & 12 \\
\hline $\mathrm{Az} 6$ & 12 & 3 & & & & 15 \\
\hline Az 71a & 5 & 4 & 4 & & 2 & 15 \\
\hline $\mathrm{Az} 71 \mathrm{~b}$ & 3 & 1 & & & 6 & 10 \\
\hline $\mathrm{Az} 75$ & & 5 & 2 & & & 7 \\
\hline Pl M 3 & & & 23 & & & 23 \\
\hline $\mathrm{Pl} \mathrm{M} 4$ & & & 24 & & & 24 \\
\hline \multirow{2}{*}{ Total } & 22 & 13 & 53 & 12 & 10 & \multirow{2}{*}{110} \\
\hline & \multicolumn{2}{|c|}{35} & 53 & 12 & 10 & \\
\hline
\end{tabular}

${ }^{14}$ Total de zampoña por sitio arqueológico.

${ }^{15} \mathrm{El}$ dígito 2 y siguientes se lee como que en el sitio Az. 141 existen 2 zampoñas asociadas a la fase cultural Cabuza y por tanto al período Medio. 
Una primera lectura de la tabla precedente señala que las zampoñas hacen su aparición durante el período Medio. La segunda indica que la mayor cantidad de sicus analizados están vinculados al período Intermedio Tardío, luego con el período Medio y finalmente con el Inca. No obstante, se debe recordar que el número de contextos analizados no es homogéneo para cada período cultural, lo que distorsiona esta lectura. De allí que se haga necesario contrastar dichos números mediante una relación porcentual con los contextos de procedencia.

TABLA N ${ }^{\circ} 5$

RELACIÓN: CONTEXTOS CULTURALES - PERÍODOS - FASES CULTURALES

\begin{tabular}{|c|c|c|c|c|c|c|}
\hline Períodos & \multicolumn{2}{|c|}{ Medio } & Intermedio Tardío & Tardío & No determinado & \\
\hline Fases & Cabuza & Maytas & San Miguel / Gentilar & Inca & No Determinada & Total \\
\hline \multirow{2}{*}{ Contextos } & 319 & 66 & 369 & 73 & 200 & 1027 \\
\cline { 2 - 7 } & \multicolumn{2}{|c}{385} & 369 & 73 & 200 & 1027 \\
\hline
\end{tabular}

TABLA $\mathrm{N}^{\circ} 6$

RELACIÓN: INSTRUMENTOS MUSICALES (ZAMPONAS) PERÍODOS - FASES CULTURALES

\begin{tabular}{|c|c|c|c|c|c|c|}
\hline Períodos & \multicolumn{2}{|c|}{ Medio } & Intermedio Tardío & Tardío & No determinado & \\
\hline Fases & Cabuza & Maytas & San Miguel / Gentilar & Inca & No determinada & Total \\
\hline \multirow{2}{*}{ Zampoñas } & 22 & 13 & 53 & 12 & 10 & 110 \\
\cline { 2 - 7 } & \multicolumn{2}{|c}{35} & 53 & 12 & 10 & 110 \\
\hline
\end{tabular}

Las tablas precedentes presentan los antecedentes que debemos analizar para obtener una lectura más apropiada de las relaciones crono-culturales de las zampoñas prehispánicas en el extremo norte de Chile. Dicha lectura deberá entonces ser el resultado de una relación porcentual entre la tabla a y la b, la que se traduce en que a cierta cantidad de contextos culturales, corresponde un determinado número de zampoñas.

TABLA $\mathrm{N}^{\circ} 7$

RELACIÓN PORCENTUAL DE ZAMPOÑAS / CONTEXTOS CULTURALES POR PERÍODOS

\begin{tabular}{|c|c|c|c|}
\hline Período & $\mathbf{N}^{\circ}$ zampoñas & $\mathbf{N}^{\circ}$ contextos & Relación \% \\
\hline Medio & 35 & 385 & $9,1 \%$ \\
\hline Intermedio Tardío & 53 & 369 & $14,4 \%$ \\
\hline Tardío & 12 & 73 & $16,4 \%$ \\
\hline
\end{tabular}

La tabla señala que el $9,1 \%$ de los contextos del período Medio presentan zamponas; durante el período Intermedio Tardío el 14,4\% y, durante el período 
Tardío el 16,4\%. Existe también un porcentaje de 5,0\% de zampoñas en contextos sin determinar.

TABLA 8

FRECUENCIA PORCENTUAL DE ZAMPOÑAS POR CADA 100 CONTEXTOS SEGÚN PERÍODOS CULTURALES

\begin{tabular}{|c|c|c|c|c|}
\hline Períodos & \multicolumn{3}{|c|}{$\begin{array}{c}\text { Frecuencia \% de zamponas } \\
\text { por períodos }\end{array}$} & Años \\
\hline Período Tardío & \multicolumn{3}{|c|}{$16,4 \%$} & $1400-1500$ d.C. \\
\hline $\begin{array}{c}\text { Período Intermedio } \\
\text { Tardío }\end{array}$ & & $14,4 \%$ & $1000-1400$ d.C. \\
\hline Período Medio & $9,1 \%$ & & $500-1000$ d.C. \\
\hline
\end{tabular}

\section{COMENTARIOS}

El uso de los aerófonos de filo popularmente conocidos como zampoñas en el área andina posee una tradición de larga data temporal en el caso específico del área andina del norte chileno. Los contextos arqueológicos estudiados evidencian la utilidad y significación de los instrumentos musicales como artefactos culturales generados de sonoridades tanto en prácticas festivas como en actividades cúlticas circunscritas a ritos mortuorios.

La presencia de aerófonos de origen precolombino como las lacas o sikus (zampoña) en Arica han permitido analizar la evidencia material sobre la utilización de instrumentos musicales en las sociedades andinas, además de identificar las características de estos y los contextos en los cuales se insertan. Lo anterior demuestra que la musicalización en cuanto a prácticas sociales y rituales propiamente tal, de acuerdo con los registros arqueológicos y a la documentación etnohistórica, posee larga data en el norte del país. Asimismo, estos antecedentes nos abren la discusión para pesquisar algunos aspectos desconocidos sobre los instrumentos musicales andinos. Estos han sido descritos como artefactos folclóricos, sin profundizar con datos concretos sobre los soportes socioculturales y simbólicos que ellos representan.

Sintetizando los antecedentes analizados es posible enunciar algunos componentes relevantes de los aerófonos andinos aquí estudiados. A saber:

1. Los instrumentos que hemos identificado con la expresión popular de zampoñas aparecen en los registros arqueológicos del valle de Azapa a partir del período cultural asociado a la expansión del estado altiplánico de Tiwanaku, cuyas dataciones lo sitúan entre los años 500 y 1000 d.C. Esto podría significar una propagación del uso de los aerófonos en toda el área andina debido a la influencia cultural y simbólica de Tiwanaku.

2. Las zampoñas datadas para el período Tiwanaku en Azapa se presentan como un artefacto cultural recurrente en el ajuar mortuorio. No obstante, un análisis detallado de los contextos asociados señala que las zampoñas no constituyeron 
FOTOGRAFÍAS DE ZAMPOÑAS DE LA COLECCIÓN DEL MUSEO DE AZAPA, ARICA.

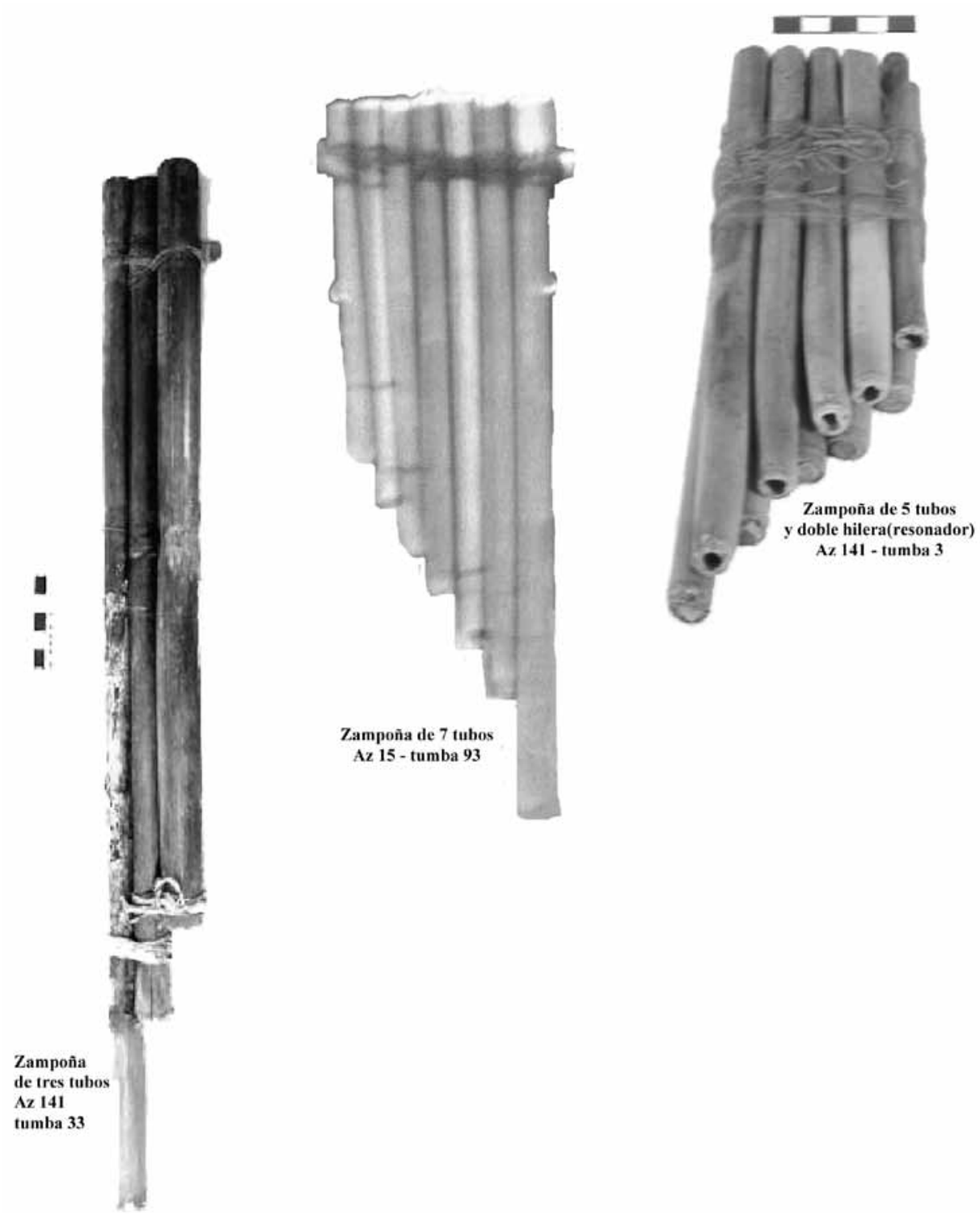

un elemento masivo en la ofrenda funeraria, sino más bien corresponderían a un bien escaso. De hecho, la media de estos en relación con los contextos analizados alcanza solo a un $8,02 \%$, es decir, que de cada 100 contextos, 8 de ellos fueron ofrendados con zampoñas en contextos mortuorios. Es dable conjeturar que su escasez respondería, al parecer, a un bien simbólico traído por señores tiwanakotas al área de Arica, o a objetos de un alto valor simbólico 
y cultural a los que solo algunos miembros de las comarcas locales de Azapa pudieron acceder como parte de su influencia sociopolítica y/o religiosa en el área. Sin perjuicio de lo anterior, las zampoñas pudieron ser artefactos de ofrendas a ciertos personajes influyentes de las aldeas de los valles occidentales, que recibieron la ofrenda ritual en los contextos fúnebres.

3. Con el paso de los años, las zampoñas fueron adquiriendo una mayor popularidad como parte de la ofrenda funeraria en los cementerios de Azapa, llegando a tener una frecuencia del $16 \%$ durante el período de influencia del Tawantinsuyu. Tanto la evidencia del material arqueológico precolombino como la información documental, grafican in extenso los diferentes usos que los aerófonos tuvieron en todas las regiones de la influencia sociopolítica, cultural e ideológica del estado Inca, tal como fue descrita en las crónicas y relatos durante la época colonial hispana en los Andes.

Falta por resolver el tema de las tonalidades en las zampoñas precolombinas. Esta temática la hemos comenzado a desarrollar en cuanto a metodologías pertinentes, además del relevamiento de información etnográfica para contraponer los datos contemporáneos del uso de zampoñas (lacas, sikus) en los diferentes ritos y festividades celebradas en el norte de Chile. Estas investigaciones la hemos iniciado hace algunos años y próximamente publicaremos los resultados obtenidos durante largas temporadas de trabajo en terreno y en laboratorios (Díaz 2008).

Como colofón, es necesario exponer que las zampoñas acompañaron en el pasado prehispánico, y aun lo hacen, las diferentes actividades ceremoniales de las poblaciones indígenas, llevando el viejo sonido de los cañutos andinos entre los vientos cordilleranos.

\section{BIBLIOGRAFÍA}

Allison, Marvin, Guillermo Foccacci, Bernardo Arriaza, Vivien Standen, María RiVERA Y JEROLD LOWENSTEIN

1984 "Chinchorro momias de preparación complicada: métodos de momificación", Chungara, Revista de Antropología Chilena, 13. Arica, pp. 155-173.

Álvarez, Bartolomé

1588 [1998] De las costumbres y conversión de los indios del Perú. Memorial a Felipe II. Madrid:

Ediciones Polifemo.

Arriaza, Bernardo

1995 Beyond Death. The Chinchorro Mummies of Ancient Chile. Washington D.C: Smithonian Institution Press.

2003 Cultura Chinchorro. Las momias más antiguas del mundo. Santiago: Editorial Universitaria.

Berenguer, José

2000 Tiwanaku. Señores del Lago Sagrado. Santiago: Museo Chileno de Arte Precolombino.

2004 Caravanas, interacción y cambio en el Desierto de Atacama. Santiago: Sirawi ediciones, Museo Chileno de Arte Precolombino. 
Berenguer, José y Percy Dauelsberg

1989 "El norte de Chile en la órbita de Tiwanaku", en Prehistoria de Chile. Desde sus origenes hasta los albores de la Conquista. Jorge Hidalgo, Virgilio Schiappacasse, Carlos Aldunate e Ivan Solimano (editores). Santiago: Editorial Andrés Bello, pp. 129-180.

Bertonio, Ludovico

1984 [1612] Vocabulario de la lengua Aymara, Juli, Provincia de Chucuito, Perú. Cochabamba, Bolivia: Centro de Estudios de la Realidad Económica y Social CERES, Instituto Francés de Estudios Andinos IFEA, Museo Nacional de Etnografía y Folklore MUSEF.

BitTMan, Bente

1982 "Revisión del problema Chinchorro", Chungara, Revista de Antropología Chilena, 19. Arica, pp. 46-79.

Bittman, Bente y Juan Munizaga

1976 "The Earliest Artificial Momification in the World?", A study of the Chinchorro Complex in the Northern Chile, Folk, vol.18, pp. 61-92.

1977 "Algunas consideraciones en torno al Complejo Chinchorro (Chile)", en Actas del VII Congreso Nacional de Arqueología Chilena (1). Santiago: Ediciones Kultrun, pp. 119-130.

Cieza de León, Pedro

1553 [1880] Primera parte de la crónica del Perú. Montesdoca, Sevilla: Marcos Jiménez de la Espada [Biblioteca Hispano-Ultramarina]. Madrid: Imprenta Manuel Ginés Hernández.

Chacama, Juan

2001 “Integración andina”, en Pueblos del Desierto. Entre el Pacífico y los Andes. Tarapacá: Ediciones Universidad de Tarapacá, pp.51-64.

2004 "El Horizonte Medio en los valles occidentales del norte de Chile (ca.500-1.200 d.C.)", Chungara, Revista de Antropología Chilena, 36. Arica. Suplemento especial I, (septiembre), pp. 227-233.

Chacama Juan y Gustavo Espinosa

2000 "La ruta de Tarapacá. Análisis de un mito y una imagen rupestre en el norte de Chile”, en Actas del XIV Congreso Nacional de Arqueología Chilena. Tomo I. Copiapó: Sociedad Chilena de Arqueología, pp. 769-792.

Cobo, Bernabé

1653 [1964] Historia del Nuevo Mundo [Biblioteca de Autores Españoles. Volumen II. Obras del Padre Bernabé Cobo (II) ]. Madrid: Atlas.

Córdova, Julia, Juan Chacama y Ana María Carrasco

2008 Arica cultura milenaria. Santiago: Centro Cultural Palacio de La Moneda.

Covarrubias Orozco, Sebastián de

1611 [2006] Segunda parte del Tesoro de la lengua castellana. Madrid, Alicante: Biblioteca Virtual Miguel de Cervantes, Biblioteca Nacional.

Dauelsberg, Percy

1985 "Faldas del Morro: fase cultural agro-alfarera temprana", Chungara, Revista de Antropología Chilena, 14. Arica, pp. 7-44. 
Díaz, Alberto

2001 "La presencia arqueológica de zampoñas en los valles bajos de Arica. El aporte de Guillermo Focacci Aste”, Revista Diálogo Andino, № 19, pp. 79-84.

2008 "Alférez, cargos y fiesta patronal entre las comunidades andinas del norte de Chile", ponencia presentada en el $4^{\circ}$ Congreso Internacional sobre Organización Social Tradicional, Escuela Nacional de Antropología e Historia (ENAH), México D.F. (manuscrito sin edición).

Díaz, Alberto y Carlos Mondaca

1998 "Toquen, soplen sin parar. Antecedentes etnomusicológicos de las lacas tarapaqueñas", Revista Percepción, No 2, pp. 73-94.

FOCACCI, GUILLERMo

1974 "Excavaciones en el cementerio Playa Miller 7. Arica (Chile)", Chungara, Revista Chilena de Antropología, 3. Arica, pp. 23-74.

1993 "Excavaciones arqueológicas en el cementerio Az.6, valle de Azapa. Primera parte, Fase Cabuza", Chungara, Revista de Antropología Chilena, 34-35. Arica, pp. 69-123.

Garcilaso de la Vega, Inca

1609 [1991] Comentarios reales de los Incas. Lima: Fondo de Cultura Económica.

Golsdtein, Paul

1989 Omo a Tiwanaku Provincial Centers in Moquegua, Peru. Disertación presentada para la obtención del grado de doctor. Universidad de Chicago: Departmento de Antropología.

1995/96 "Tiwanaku Settlement Patterns of the Azapa Valley, Chile. New Data and the Legacy of Percy Dauelsberg", Diálogo Andino, No 14-15, pp. 95-73.

Gonçalez Holguín, Diego

1608 [1952] Vocabulario de la lengua general de todo el Perú llamada lengua Quichua o del Inca. Lima: Edición del Instituto de Historia/ Imprenta Santa María.

Grebe, María Ester

1974 "Instrumentos musicales precolombinos de Chile", RMCh, XXXVIII/128 (octubrediciembre), pp. 5-55.

Guamán Poma de Ayala, Felipe

1615 [1992] El primer nueva coronica y buen gobierno. Edición a cargo de John V. Murra, Rolena Adorno y Jorge Urioste, México: Siglo XXI Editores.

Hidalgo, Jorge, Virgilio Schiappacasse, Hans Niemeyer, Carlos Aldunate e Iván Solimano (EDitores)

1989 Prehistoria de Chile, Desde sus orígenes hasta los albores de la Conquista. Santiago: Editorial Andrés Bello.

Kolata, Alan

1993 The Tiwanaku. Portrait of an Andean Civilization. Cambridge: Blackwell.

Llagostera, Agustín

1976 "Hipótesis sobre la expansión incaica en la vertiente occidental de los Andes Meridionales", en Homenaje al Dr. Rev. Padre Gustavo Le Paige. Antofagasta: Universidad del Norte, pp. 203-218. 
1979 "9.700 years of Maritime Subsistence on the Pacific: an Analysis by Means of Bioindicator in the North of Chile", American Antiquity, XLIV/2. Washington, DC, pp. 217-245.

1982 "Tres dimensiones en la conquista prehistórica del mar", en Actas del VIII Congreso Nacional de Arqueología Chilena (1979). Santiago: Editorial Kultrún.

1989 "Pesca y caza marítima (9.000 a 1.000 a.C.)”, en Jorge Hidalgo, Virgilio Schiappacasse, Hans Niemeyer, Carlos Aldunate e Iván Solimano (editores). Prehistoria de Chile. Desde sus orígenes hasta los albores de la conquista. Santiago: Editorial Andrés Bello, pp. 57-80.

MuÑoz, IVÁN

1989 "El período Formativo en el Norte Grande (100 a.C. a 500 d.C.), en Jorge Hidalgo, Virgilio Schiappacasse, Hans Niemeyer, Carlos Aldunate e Iván Solimano (editores), op. cit., pp. 107-128.

2002 En torno a la formación del proceso Aldeano en los valles desérticos del Norte de Chile: El caso del Valle de Azapa. Tesis para optar al grado de Doctor en Arqueología. México D.F.: Universidad Nacional Autónoma de México.

2004a Estrategias de organización prehispánica en Azapa: el impacto de la agricultura en un valle del desierto costero del Pacífico. Tarapacá: Ediciones Universidad de Tarapacá, Arica.

2004b "El período Formativo en los valles del norte de Chile y sur del Perú: nuevas evidencias y comentarios", Chungara, Revista de Antropología Chilena, 36. Arica Suplemento especial I (septiembre), pp. 213-225.

Muñoz, Iván y Juan Chacama

1982 Investigaciones arqueológicas en las poblaciones precerámicas de la costa de Arica [Documentos de Trabajo 2]. Tarapacá: Universidad de Tarapacá, pp. 5-95.

1993 "Patrón de asentamiento y cronología de Acha-2", en Iván Muñoz, Bernando Arriaza y Arturo Aufderheide (editores). Acha 2 y los origenes del poblamiento humano en Arica. Tarapacá: Ediciones Universidad de Tarapacá, pp. 21-46.

1997 "Acha-2, 9.000 años de tradición pescadora-recolectora en el norte de Chile", en Térèsse Bouysee-Cassagne (editora). Saberes y memorias en los Andes, Travaux de l'IFEA. París: Instituto de Estudios Andinos. Tomo 97, pp. 21-39.

2006 Complejidad social en las alturas de Arica: territorio, etnicidad y vinculación con el estado Inka. Tarapacá: Ediciones Universidad de Tarapacá.

Muñoz, Iván, Juan Chacama, Gustavo Espinosa y Luis Briones

1987a "La ocupación prehispánica tardía en Zapahuira y su vinculación a la organización económica y social Inca”, Chungara, Revista de Antropología Chilena, 18. Arica, pp. 67-89.

Muñoz, Iván, Juan Chacama y Gustavo Espinosa

1987b "El poblamiento prehispánico tardío en el valle de Codpa. Una aproximación a la prehistoria regional”, Chungara, Revista de Antropología Chilena, 19. Arica, pp. 7-69.

Mujica Elías, Mario Rivera y Tom Lynch

1983 "Proyecto de estudios de la complementariedad económica de Tiwanaku, en los valles occidentales del área Centro Sur Andina”, Chungara, Revista de Antropología Chilena, 11. Arica, pp. 85-109. 
Niemeyer, Hans y Virgilio Shiappacasse

1988 "Patrones de asentamiento incaicos en el norte Grande de Chile", en Tom Dillehay y Patricia Netherly (editores). La frontera del estado Inca. Oxford: BAR International Series, pp. 141-180.

NúÑEz, LaUtaro

1976 "Geoglifos y tráfico de caravanas en el desierto chileno", en Hans Niemeyer (editor). Homenaje al Dr. Rev. Padre Gustavo Le Paige. Antofagasta: Universidad del Norte, pp. 147-201.

\section{Núñez, Lautaro y Tom Dillehay}

1978 Movilidad giratoria, armonía social y desarrollo en Los Andes Meridionales: patrones de tráfico e interacción económica. Antofagasta: Universidad del Norte.

Pérez de Arce, José

1995 Música en la piedra. Santiago: Museo Chileno de Arte Precolombino.

Rivera, Mario

1980 Algunos fenómenos de la complementariedad económica a través de los datos arqueológicos en el área centro sur andina: la fase Alto Ramírez reformulada [Temas Antropológicos del Norte de Chile. Editado por Mario Rivera]. Antofagasta: Universidad de Chile.

1984 "Alto Ramírez y Tiwanaku. Un caso de interpretación simbólica a través de datos arqueológicos en el área de los valles occidentales, sur del Perú y norte de Chile”, Diálogo Andino, 4, pp. 39-71.

1995 "The Preceramica Chinchorro Mummy Complex of Northern Chile: Context, Style and Purpose", en Tom Dillehay (editor). Tombs for the Living: Andean Mortuory Practices. Washington D.C: Dumbarton Oaks Research Library and Collection.

Santoro, Calogero

1980a "Estratigrafía y secuencia cultural funeraria: fase Azapa, Alto Ramírez y Tiwanaku, (Arica, Chile)", Chungara, Revista de Antropología Chilena, 6. Arica, pp. 24-45.

1980b "Fase Azapa. Transición del Arcaico al desarrollo agrario inicial en los valles bajos de Arica", Chungara, Revista de Antropología Chilena, 6. Arica, pp. 46-56.

1980c Estudios de un yacimiento funerario arqueológico del extremo norte de Chile, 1300 a.C.1300 d.C. Tesis no publicada para optar al título de arqueólogo. Antofagasta: Departamento de Arqueología, Universidad del Norte.

1981 "Formativo temprano del extremo norte de Chile", Chungara, Revista Chilena de Antropología, 8. Arica, pp. 33-62.

1989 “Antiguos cazadores de la Puna”, en Jorge Hidalgo, Virgilio Schiappacasse, Hans Niemayer, Carlos Aldunate e Iván Solimano (editores). Culturas de Chile. Prehistoria. Desde sus orígenes hasta los albores de la Conquista. Santiago: Editorial Andrés Bello, pp. 107-128.

2000 "El Formativo en la región de valles occidentales del área centro surandina (sur Perú - norte de Chile)", en Paulina Lederberger-Crespo (editor). Formativo Sudamericano. Quito: Ediciones Abya Ayala, pp. 243-254.

2001 “Caciques y control territorial”, en Pueblos del desierto. Tarapacá: Ediciones Universidad de Tarapacá, pp. 65-72. 
Santoro, Calogero y Lautaro Núñez

1987 "Hunters of the Dry Puna and Salt Puna in the Northern Chile", Andean Past, 1, pp. $57-110$.

Santoro, Calogero y Liliana Ulloa (editores)

1985 Culturas de Arica [Serie Patrimonio Cultural Chileno. Colección Culturas Aborígenes]. Santiago.

Santoro, Calogero, Elians Belmonte, Vivien Standen, Juan Chacama, Jorge Hidalgo, Luis Briones, Liliana Ulloa, Héctor González.

2001 Pueblos del desierto. Entre el Pacífico y los Andes. Tarapacá: Ediciones Universidad de Tarapacá [Departamento de Arqueología y Museología].

Schiappacasse, Virgilio, Victoria Castro y Hans Niemeyer

1989 "Los desarrollos regionales en el Norte Grande", en Jorge Hidalgo, Virgilio Schiappacasse, Carlos Aldunate e Iván Solimano (editores). Prehistoria de Chile. Desde los orígenes hasta los albores de la Conquista. Santiago: Editorial Andrés Bello, pp. 181-220.

Schiappacasse, Virgilio y Hans Niemeyer

1997 "Continuidad y cambio cultural en el poblado actual, colonial e inca de Pachica, Quebrada de Camarones", Chungara, Revista de Antropología Chilena, XXVIII/1 y 2. Arica, pp. 209-247.

2002 "Ceremonial Inca provincial: El asentamiento de Saguara (Cuenca de Camarones)", Chungara, Revista de Antropología Chilena, XXXIV/1. Arica, pp. 53-84.

STANDEN, Vivien

1991 El cementerio Morro 1. Nuevas evidencias de la tradición funeraria Chinchorro (periodo Arcaico norte de Chile). Tesis de maestría. Lima: Universidad Católica de Lima.

Standen, Vivien, Marvin Allison y Bernardo Arriaza

1984 "Patologías óseas de la población Morro 1, asociada al complejo Chinchorro: norte de Chile”, Chungara, Revista de Antropología Chilena, 15. Arica, pp. 197-209.

2004 "Síntesis y propuestas para el Período Arcaico en la costa del extremo norte de Chile”, Chungara, Revista de Antropología Chilena, 36. Arica, suplemento especial, I, (septiembre), pp. 201-212.

Uribe, Mauricio

1999 "La cerámica de Arica 40 años después de Dauelsberg", Chungara, Revista de Antropología Chilena, XXXI/2. Arica, pp. 189-228.

2004 "El Inka y el poder como problema de la Arqueología del norte grande de Chile", Chungara, Revista de Antropología Chilena, XXXVI/2. Arica, pp. 313-324.

Uribe, MaUricio y LeONOR AdÁN

2004 “Acerca del dominio Inka, sin miedo, sin vergüenza”, Revista Chilena de Antropología, XXXVI, suplemento especial I (septiembre), pp. 467-480. 